\title{
Evaluation of Indoor Air Pollution during the Decorating Process and Inhalation Health Risks in Xi'an, China: A Case Study
}

\author{
Tian Chang ${ }^{1}$, Jinhui Wang ${ }^{2}$, Jiaqi Lu ${ }^{1}$, Zhenxing Shen ${ }^{1 *}$, Yu Huang ${ }^{3}$, Jian Sun ${ }^{1}$, Hongmei Xu ${ }^{1}$, \\ Xin Wang ${ }^{4}$, Dongxiao Ren ${ }^{1}$, Junji Cao ${ }^{3}$ \\ ${ }^{1}$ Department of Environmental Sciences and Engineering, Xi'an Jiaotong University, Xi'an 710049, China \\ ${ }^{2}$ NICU, Xi'an Children's Hospital, Xi'an 710003, China \\ ${ }^{3}$ Key Lab of Aerosol Chemistry \& Physics, SKLLQG, Institute of Earth Environment, Chinese Academy of Sciences, Xi'an \\ 710049, China \\ ${ }^{4}$ Multiphase Chemistry Department, Max Planck Institute for Chemistry, Mainz, 55128, Germany
}

\begin{abstract}
$\mathrm{PM}_{2.5}$, formaldehyde, and 8 volatile organic compounds (VOCs) were observed in 6 newly decorated apartment units to evaluate the effects of the decorating process on the indoor air quality in Xi'an, China. The comparison of indoor and outdoor formaldehyde and VOCs concentrations showed that the outdoor $\mathrm{PM}_{2.5}$ concentration exceeded the indoor one during the monitoring process, whereas the indoor formaldehyde and VOCs concentrations exceeded the outdoor ones. The levels of formaldehyde and VOCs in different rooms were investigated, and the concentrations in the bedroom were found to be the highest. Furthermore, the formaldehyde and VOCs concentrations were measured in 200 other rooms decorated within a 2-year period in Xi'an, and the results indicated that wallpapering, wooden flooring, and furniture were the major decorating processes emitting these compounds. In addition, a health risk assessment of the monitored formaldehyde and VOCs in the rooms 1 year after decorating showed that benzene posed the greatest health risk among the assessed VOCs.
\end{abstract}

Keywords: Indoor air quality; Decorating process; Inhalation health risks; Xi'an.

\section{INTRODUCTION}

Indoor air quality is considered to be a major environmental issue given that indoor air pollution has significant detrimental health effects (Batterman et al., 2012a; Verriele et al., 2016; Zorpas and Skouroupatis, 2016). Indoor air quality is important because of the following two reasons. On the one hand, people spend almost $90 \%$ of their days in enclosed living spaces (Gong et al., 2017). On the other hand, indoor air pollutants accumulate more easily because the indoor environment contains many pollution sources and indoor air flows slowly (Pei et al., 2013; Bourdin et al., 2014). Among the indoor air pollutants, formaldehyde and volatile organic compounds (VOCs) have been recognized as detrimental constituents because of human health effects, including their non-cancer or cancer risks. The dominant non-cancer chronic effects of formaldehyde and VOCs are headache, cough, nausea, severe liver poisoning, asthma and other respiratory effects

\footnotetext{
${ }^{*}$ Corresponding author.

E-mail address: zxshen@mail.xjtu.edu.cn
}

(Rumchev et al., 2007; Dai et al., 2017), whereas cancer affects mainly include the brain, liver, lung, blood (leukemia and non-Hodgkin lymphoma), kidney, and biliary tract cancers (WHO, 2000; He et al., 2015). Formaldehyde and VOCs can be taken up by the human body through inhalation, ingestion, and via the dermis, with inhalation being a predominant uptake route (Guo et al., 2004; Lee et al., 2006; Rumchev et al., 2007). Of the wide variety of indoor sources, building materials, decorative materials, and furniture constitute important sources for indoor air pollution (Zhang et al., 2016; Cheng et al., 2017). Many countries have established labeling schemes to reduce indoor emissions from building products (Kephalopoulos et al., 2006). In addition, fine particulate matter (PM) also comprises a large group of indoor air compounds, which mainly harm the respiratory and cardiovascular systems (Batterman et al., 2012b; Mehta et al., 2013; Petkova et al., 2013; Song et al., 2015; Dickerson et al., 2017; Tong et al., 2018).

Extensive investigations have been conducted on the indoor $\mathrm{PM}_{2.5}$, formaldehyde and VOCs concentration, especially for formaldehyde and total volatile organic compounds (TVOC) concentrations (Afshari et al., 2003; Chang et al., 2017). Recent studies have shown that formaldehyde and the VOCs concentrations in new homes 
were higher than that in older homes (Park and Ikeda, 2006). Han et al. (2015) reported that outdoor $\mathrm{PM}_{2.5}$ concentrations influenced indoor $\mathrm{PM}_{2.5}$ concentrations significantly. Chi et al. (2016) reported that TVOC and formaldehyde originated mainly from volatile sources by pollution generation during decoration. Tao et al. (2015) proposed that the formaldehyde and TVOC concentrations were inversely proportional to indoor air velocity and in direct proportion to the indoor temperature and relative humidity. Sofuoglu et al. (2011) measured the VOCs concentrations and estimated associated health risks in schools, and formaldehyde was found to be the main concern with high chronic toxic and carcinogenic risk levels followed by naphthalene, benzene, and toluene among the measured VOCs. However, almost all previous studies focused on pollutant concentrations at a laboratory scale or in rooms that had been decorated several years previously. Limited studies exist on the $\mathrm{PM}_{2.5}$ concentration, formaldehyde and VOCs emission characteristics during decorating. It is necessary to identify the formaldehyde and VOCs emission sources to obtain a better understanding of their emission characteristics during the decorating process. The inhalation-related health risks of formaldehyde and VOCs in newly decorated apartment units have not been well studied in Xi'an. Thus, a deeper understanding of the potential adverse health effect of formaldehyde and VOCs in newly decorated apartment units is required urgently.

This study was designed to investigate the $\mathrm{PM}_{2.5}$, formaldehyde and VOCs (including benzene, toluene, $o$-xylene, $p$-xylene, $n$-butyl acetate, ethylbenzene, styrene, and $n$-undecane) emission characteristics during the decoration process of 6 residential apartment units (24 rooms) in Xi'an. Eight compounds were selected as the target VOCs, including benzene, toluene, $o$-xylene, $p$-xylene, $n$-butyl acetate, ethylbenzene, styrene, and $n$-undecane. The purpose of our study was to (1) compare the indoor and outdoor $\mathrm{PM}_{2.5}$, formaldehyde and VOCs concentrations, (2) obtain formaldehyde and VOCs concentrations variations as a function of the decorating process, (3) explore the influence of decorating materials on formaldehyde and VOCs emissions, and (4) estimate the health risk of formaldehyde and the selected VOCs (benzene, toluene, $o$-xylene, $p$-xylene, styrene and ethylbenzene) in rooms 1 year after decoration.

\section{MATERIALS AND METHODS}

\section{General Information of Sampling Sites}

Air sampling was conducted in Xi'an, China, from March 2014 to November 2017. 6 apartment units that were decorated with different materials were selected and their air quality was monitored at different decorating stages. 4 rooms, including the bedroom, living room, kitchen, and bathroom were selected from each house. The detailed characterizations of the selected apartment units were presented in Table 1. For a more precise investigation of the influence of decoration materials and the health effect of formaldehyde and the selected VOCs, formaldehyde and the given VOCs concentrations were measured in 200 other rooms in this study. These rooms were decorated within 2 years.

\section{Sampling and Analytical Methods}

Air pollutants, including formaldehyde, benzene, toluene, $o$-xylene, $p$-xylene, $n$-butyl acetate, styrene, ethylbenzene, $n$-undecane, and respirable suspended particulate $\left(\mathrm{PM}_{2.5}\right)$ matter were studied. Indoor and outdoor air samples were collected simultaneously in the selected homes and outdoor sampling sites were located near the monitored apartment units during the decorating process. The sampling and analysis methods of formaldehyde and VOCs were based on China's GB/T 18883-2002 indoor air quality standard. Before sampling, the flow of the sampling instrument was calibrated by a mass flowmeter (Model 4140, TSI Inc., USA). The stainless steel tubes for VOCs sampling were activated by the thermal desorption unit for $1 \mathrm{~h}$ at $350^{\circ} \mathrm{C}$ in the pure $\mathrm{N}_{2}$. Also of note was that all the monitored rooms were closed for $12 \mathrm{~h}$ before sampling to make sure each room was independent relatively. All the samples were collected using a sampler (QC-2, Beijing Municipal Institute of Labour Protection, China) equipped with a bubble tube for formaldehyde sampling and stainless steel tube for VOCs sampling. The stainless steel tube was filled with $200 \mathrm{mg}$ Tenax-TA absorbents (60-80 mesh). The sampler was fixed on a tripod approximately $1.5 \mathrm{~m}$ above the ground level, close to the breathing height of human. The sample flow rate and time were set as $0.5 \mathrm{~L} \mathrm{~min}^{-1}$ and $20 \mathrm{~min}$, respectively. After sampling, all the samples were

Table 1. Characteristics of sampling sites in Xi'an.

\begin{tabular}{|c|c|c|c|c|c|c|c|c|c|c|}
\hline \multirow{2}{*}{$\begin{array}{l}\text { Site } \\
\text { no. }\end{array}$} & \multirow{2}{*}{$\begin{array}{l}\text { Number } \\
\text { of floors }\end{array}$} & \multicolumn{4}{|c|}{ Area $\left(\mathrm{m}^{2}\right)$} & \multicolumn{4}{|c|}{${ }^{\mathrm{e}}$ Frequency of Ventilation } & \multirow{2}{*}{${ }^{\mathrm{f}}$ Traffic flow } \\
\hline & & $\mathrm{a}$ & $\mathrm{b}$ & $\mathrm{c}$ & $\mathrm{d}$ & $\mathrm{a}$ & $\mathrm{b}$ & $\mathrm{c}$ & $\mathrm{d}$ & \\
\hline 1 & 7 & 12 & 30 & 7 & 4 & Daily & Daily & Infrequent & Daily & Low \\
\hline 2 & 10 & 12 & 30 & 7 & 4 & Weekly & Daily & Weekly & Infrequent & Low \\
\hline 3 & 11 & 12 & 30 & 7 & 4 & Weekly & Daily & Infrequent & Infrequent & Low \\
\hline 4 & 13 & 15 & 42 & 8 & 5 & Daily & Daily & Daily & Daily & Low \\
\hline 5 & 11 & 18 & 45 & 8 & 6 & Daily & Daily & Infrequent & Infrequent & Moderate \\
\hline 6 & 28 & 18 & 45 & 8 & 6 & Weekly & Daily & Infrequent & Infrequent & Moderate \\
\hline
\end{tabular}

Note: a, bedroom; b, living room; c, kitchen; $d$, bathroom.

${ }^{\mathrm{e}}$ daily means opening windows every day; weekly means opening windows once a week; and infrequent means the frequency of opening windows is less than once a week.

${ }^{\mathrm{f}}$ low means that the apartment is not adjacent to a trafficked road; moderate means that the apartment is adjacent to a trafficked road; and high means that the apartment is adjacent to a heavily trafficked road. 
immediately transported to the laboratory for analysis. It was worth noting that the influence of $\mathrm{SO}_{2}$ was excluded by making the air samples pass the manganese sulfate paper filter before entering the formaldehyde absorption tube as described in GB/T 18204.2-2014. The $\mathrm{PM}_{2.5}$ concentrations were measured using a Dust-Trak Handheld Aerosol Monitor (Model 8520, TSI Inc., USA) at $3.0 \mathrm{~L} \mathrm{~min}^{-1}$. Before sampling, the Dust-Trak monitor was calibrated by gravimetric methods. The Dust-Trak monitor was located away from the exhaust ducts during sampling. On the testing day, field blanks were conducted for each house. The general descriptions of sampling parameters including home type, indoor temperature, pressure, relative humidity, decoration stage, and decoration materials were recorded during sampling collection.

Phenol reagent spectrophotometry was used to measure the formaldehyde concentration of the samples (GB/T 18204.2-2014). First, phenol reagent dissolved in deionized water was used to collect formaldehyde sample based on their reactions to form azine. Then, ammonium ferric sulfate dissolved in hydrochloric acid $\left(0.1 \mathrm{~mol} \mathrm{~L}^{-1}\right)$ was added into the above liquid to react with azine to form blue-green compounds. Subsequently, the above solution was allowed to stand for at least 15 minutes to react thoroughly. Finally, the formaldehyde concentration was determined by colorimetric method using a spectrophotometer (UV-2600AH, Unico, USA). VOCs concentrations of the samples were determined by a gas chromatography (GC9790, Fuli Instruments, China) equipped with a flame ionization detector, thermal desorption unit (JX-3) and quartz capillary column (SE-30, $50 \mathrm{~m} \times 0.32 \mathrm{~mm})$. For the determination of VOCs, the injector temperature was set as $240^{\circ} \mathrm{C}$. The initial temperature of $\mathrm{GC}$ oven is $50^{\circ} \mathrm{C}$, holding for 10 min, and then increased to $260^{\circ} \mathrm{C}$ at a rate of $10^{\circ} \mathrm{C} \mathrm{min}^{-1}$, then hold for $2 \mathrm{~min}$.

\section{Risk Calculation}

The risk assessment for indoor VOC inhalation exposure was based on published toxicity data and exposure concentrations measured in this study. Formaldehyde, benzene, toluene, $o$-xylene, $p$-xylene, styrene and ethylbenzene were selected as the target toxic chemicals.

Cancer risks from the formaldehyde and VOCs cannot be ignored because we spend most of our daily life indoors. We investigated the cancer risks for formaldehyde and the selected VOCs using Eqs. (1)-(2) (Guo et al., 2004; Lee et al., 2006; EPA, 2011):

$$
\begin{aligned}
& \mathrm{CR}=\mathrm{EC} \times \mathrm{SF} \\
& \mathrm{EC}=\frac{\mathrm{CA} \times \mathrm{IR} \times \mathrm{ET} \times \mathrm{EF} \times \mathrm{ED} \times \mathrm{UCF}}{\mathrm{BW} \times \mathrm{AT} \times 365}
\end{aligned}
$$

where CR, EC, SF, CA, IR, ET, EF, ED, UCF, BW and AT denote the cancer risk, exposure concentration, cancer slope factor $\left(\mathrm{kg} \mathrm{d} \mathrm{mg}^{-1}\right)$, contaminant concentration $\left(\mathrm{mg} \mathrm{m}^{-3}\right)$, inhalation rate $\left(\mathrm{m}^{3} \cdot \mathrm{day}^{-1}\right)$, exposure time $\left(\mathrm{h} \mathrm{day}^{-1}\right)$, exposure frequency (days $\mathrm{y}^{-1}$ ), exposure duration $(\mathrm{y})$, unit conversion factor (say, $\left.1 \cdot 24^{-1}\right)$, exposed body weight $(\mathrm{kg})$, and average time (70 y) (Guo et al., 2004), respectively. As referenced to the Exposure Factors Handbook of the Chinese population and previous reports (MEPC, 2013; Dai et al., 2017), the exposure frequency and exposure duration were estimated as 354 days $\mathrm{y}^{-1}$ and 5 years, respectively, and the exposure time was estimated as $15 \mathrm{~h}$ (living room, $3 \mathrm{~h}$; bedroom, $8 \mathrm{~h}$; kitchen, $3 \mathrm{~h}$; and bathroom, $1 \mathrm{~h}$ ) for adults and $20 \mathrm{~h}$ (living room, $4 \mathrm{~h}$; bedroom, $12 \mathrm{~h}$; kitchen, $0 \mathrm{~h}$; and bathroom, $1 \mathrm{~h}$ ) for children ( $<3$ years) (U.S. EPA, 2011; Pei et al., 2013; Dai et al., 2017). The U.S. EPA suggests that the standard IR values for man, woman and children are $20,18 \mathrm{~m}^{3}$ day $^{-1}$ and $5 \mathrm{~m}^{3}$ day $^{-1}$, respectively (U.S. EPA, 1994; Gratt, 1996; Guo et al., 2004; U.S. EPA, 2011), for average body masses of $70 \mathrm{~kg}$ for men, $60 \mathrm{~kg}$ for women, and $10 \mathrm{~kg}$ for children (Guo et al., 2004; Bu et al., 2016). Based on the Integrated Risk Information System (IRIS) of the EPA, the SFs of the assessed formaldehyde and VOCs were listed in Table 2.

The non-cancer risk and hazard index can be calculated by Eqs. (3)-(4) (He et al., 2015; Gong et al., 2017):

$$
\mathrm{HQ}=\frac{\mathrm{EC}}{R f D}
$$

$\mathrm{HI}=\sum_{\mathrm{i}} H Q_{\mathrm{i}}$

where $\mathrm{HQ}, R f \mathrm{D}, \mathrm{HI}$, and i represent the non-cancer risk, reference dose $\left(\mathrm{mg} \mathrm{kg}^{-1} \mathrm{day}^{-1}\right)$, hazard index, and pollutant $i$. The RfD is defined as a numerical estimate of the daily exposure to the human population, which is unlikely to cause harm during a lifetime (U.S. EPA, 1989). For a given airborne toxic contaminant, exposures below the reference level $(\mathrm{HI}=1)$ are unlikely to be connected with adverse health effects (Durmusoglu et al., 2010). The potential for adverse health effects is correlated positively with the $\mathrm{HI}$ when exposures exceed the reference dose.

\section{RESULTS AND DISCUSSION}

\section{The Difference of $\mathrm{PM}_{2.5}$, Formaldehyde, and VOCs Concentrations of Indoors and Outdoors during Different Decorating Steps}

Concentrations of indoor $\mathrm{PM}_{2.5}$ and outdoor $\mathrm{PM}_{2.5}$, formaldehyde, and VOCs in different decorating stages (hydropower finished, tile finished, putty finished, wallpaper/ painting finished, wooden floor finished, door finished, and furniture finished; 1 month after decoration, 3 months after decoration, 6 months after decoration, and 12 months after decoration) were shown in Fig. 1. The outdoor $\mathbf{P M}_{2.5}$ concentration exceeded the indoor concentration in nearly all of the decorating processes. The indoor $\mathrm{PM}_{2.5}$ concentration exceeded that of outdoors after tiling had been finished, which could imply that cement and putty were stacked in the rooms used for tiling and puttying, respectively. For formaldehyde and VOCs, the indoor concentrations were similar with or higher than the outdoor concentrations before wallpapering (painting) commenced, and these increased 
significantly after wallpapering (painting) was concluded. The indoor formaldehyde and VOCs concentrations exceeded the outdoor concentrations significantly, which indicated that formaldehyde and VOCs evaporated primarily from many decorating materials, furniture, and other household products. Among the target outdoor VOCs concentrations, toluene was the most abundant in all selected rooms, followed by benzene, ethylbenzene, $o$-xylene, $p$-xylene, styrene, $n$-butyl acetate, and $n$-undecane. However, the order of indoors differed from that of outdoors, with the concentrations of ethylbenzene tending to be higher than those of benzene after wallpapering (painting) had been completed. All above-mentioned phenomena revealed that the indoor $\mathrm{PM}_{2.5}$ was derived mainly from outdoors and that the VOCs originated mainly from decorating materials, which agreed with previous reports (Yrieix et al., 2010; Han et al., 2015; Tao et al., 2015).

\section{Emission Characteristics of Formaldehyde and the Selected VOCs from Different Decorating Steps in Rooms with Different Functions}

The emission characteristics of formaldehyde and VOCs were further investigated in rooms with different functions as they are the main cause for the detrimental quality of the indoor air environment (Wang et al., 2007). As shown in Fig. 1, indoor formaldehyde and VOCs concentrations differed significantly between rooms with different functions. Initially, the trends in indoor formaldehyde and VOCs concentrations were similar during the first three decoration stages, and then diverged gradually after wallpapering (painting) had been completed. Regardless of the decorating stage, the indoor formaldehyde and VOCs concentrations of the bedroom were consistent with or slightly higher than those of the living room, followed by kitchen and bathroom. This phenomenon could have resulted from the species and

Table 2. Related toxicity values of target health-related VOCs.

\begin{tabular}{|c|c|c|c|c|c|c|}
\hline \multirow{2}{*}{ VOCs } & \multirow{2}{*}{ CAS no. } & \multirow{2}{*}{$\begin{array}{l}\text { Group } \\
\text { ('IRAC) }\end{array}$} & \multicolumn{2}{|c|}{${ }^{\mathrm{b}} \mathrm{SF}\left(\mathrm{kg} \mathrm{d} \mathrm{mg}^{-1}\right)$} & \multicolumn{2}{|c|}{${ }^{\mathrm{c}} \mathrm{RfD}\left(\mathrm{mg} \mathrm{kg}^{-1} \mathrm{~d}^{-1}\right)$} \\
\hline & & & Value & Source & Value & Source \\
\hline formaldehyde & $50-00-0$ & 1 & - & - & 0.2 & IRIS \\
\hline benzenze & $71-43-2$ & 1 & 0.055 & IRIS & 0.004 & IRIS \\
\hline toluene & $108-88-3$ & 3 & - & - & 0.08 & IRIS \\
\hline$O$-xylene & $95-47-6$ & 3 & - & - & 0.2 & IRIS \\
\hline$p$-xylene & $108-38-3$ & 3 & - & - & & \\
\hline styrene & $100-42-5$ & $2 \mathrm{~B}$ & 0.0035 & IRIS & 0.2 & IRIS \\
\hline ehylbenzene & $100-41-4$ & $2 \mathrm{~B}$ & 0.0087 & IRIS & 0.1 & IRIS \\
\hline
\end{tabular}

${ }^{\mathrm{a}}$ IARC, International Agency for Research on Cancer; ${ }^{\mathrm{b}} \mathrm{SF}$, Slope factor (obtained from IRIS); ${ }^{\mathrm{c}} \mathrm{RfD}$, Reference dose for chronic oral exposure.

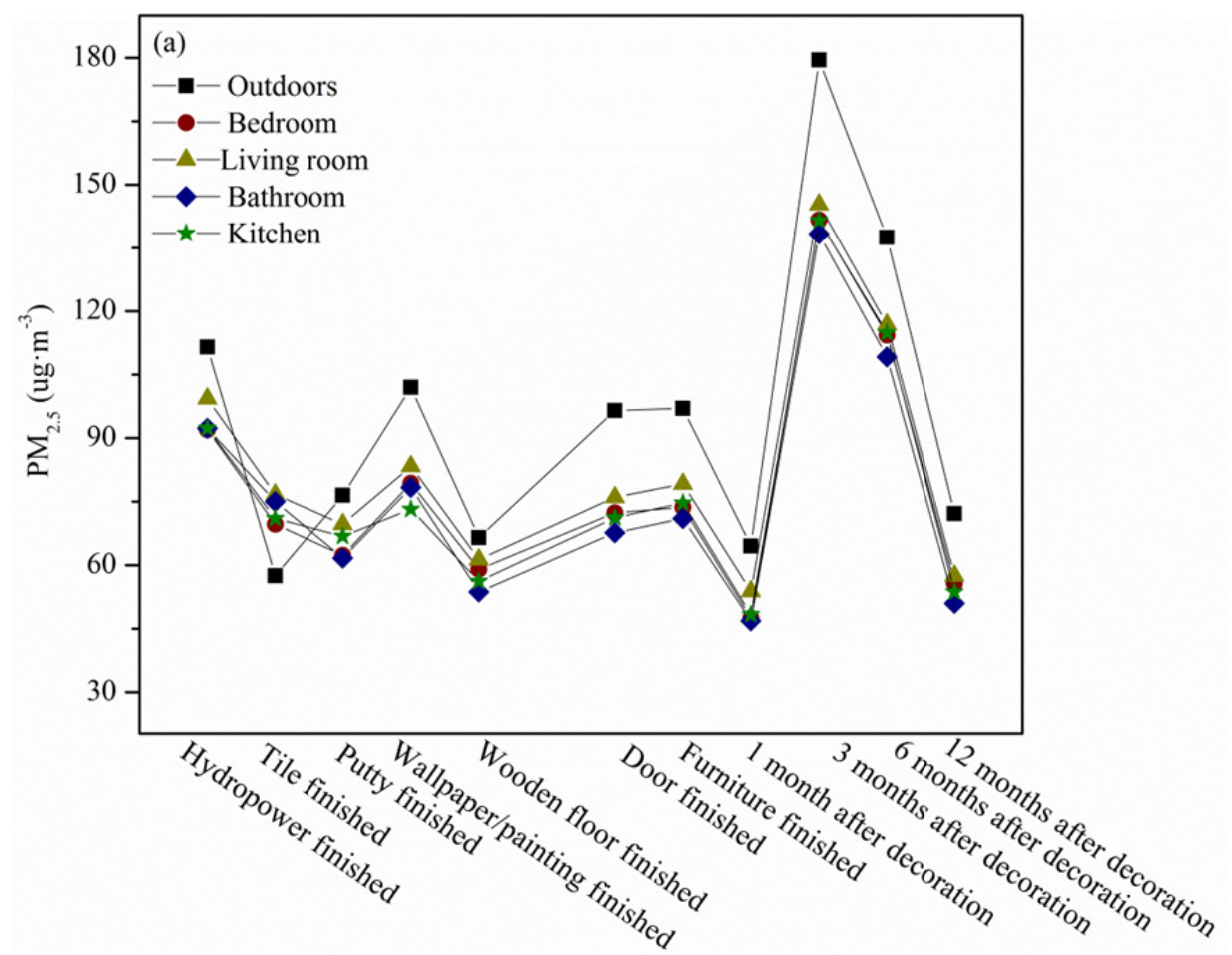

Fig. 1. Concentration of (a) $\mathrm{PM}_{2.5}$, (b) formaldehyde, and (c) VOCs in indoor and outdoor ((c): a: outdoors; b: bedroom; c: living room; d: kitchen; e: bathroom). 

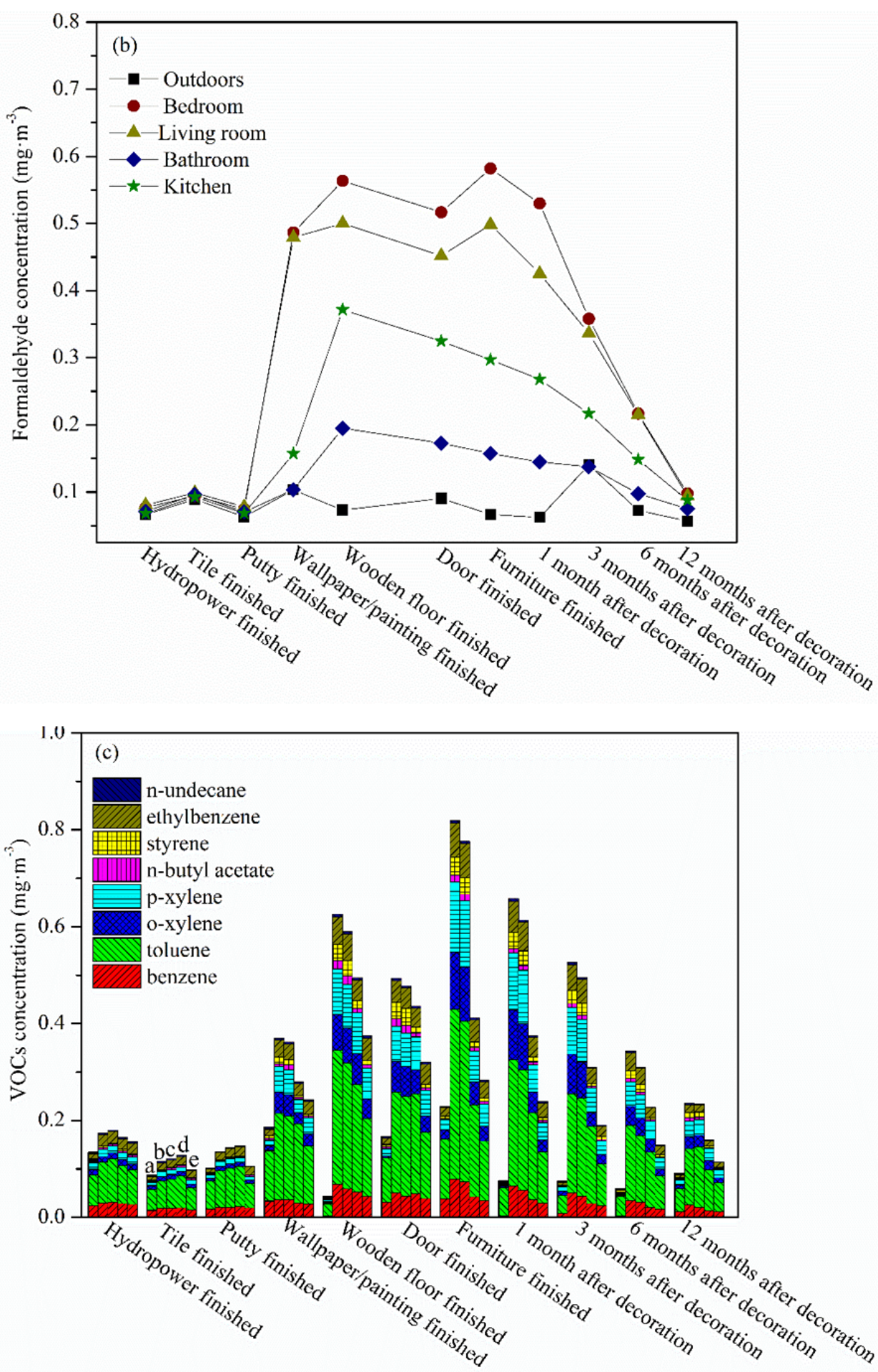

Fig. 1. (continued).

quantity of decorating materials in the living room and bedroom exceeding that of the other 2 rooms. Thus, the variations of formaldehyde and VOCs concentrations during different decorating steps were further investigated as follows.

As shown in Figs. 2-3, both the indoor formaldehyde and VOCs concentrations displayed a big difference in the different decorating stage. The indoor formaldehyde concentrations in all 4 kinds of rooms showed a sharp increase after wallpapering (painting) had been completed, especially for the living room and bedroom, whereas the indoor VOCs showed a slight increase. This phenomenon indicated that the main harmful gas releasing from wallpapering (painting) was formaldehyde. The VOCs concentrations in the living room and bedroom presented two peaks after the wooden flooring and furniture had been finished, whereas formaldehyde changed within a relatively 


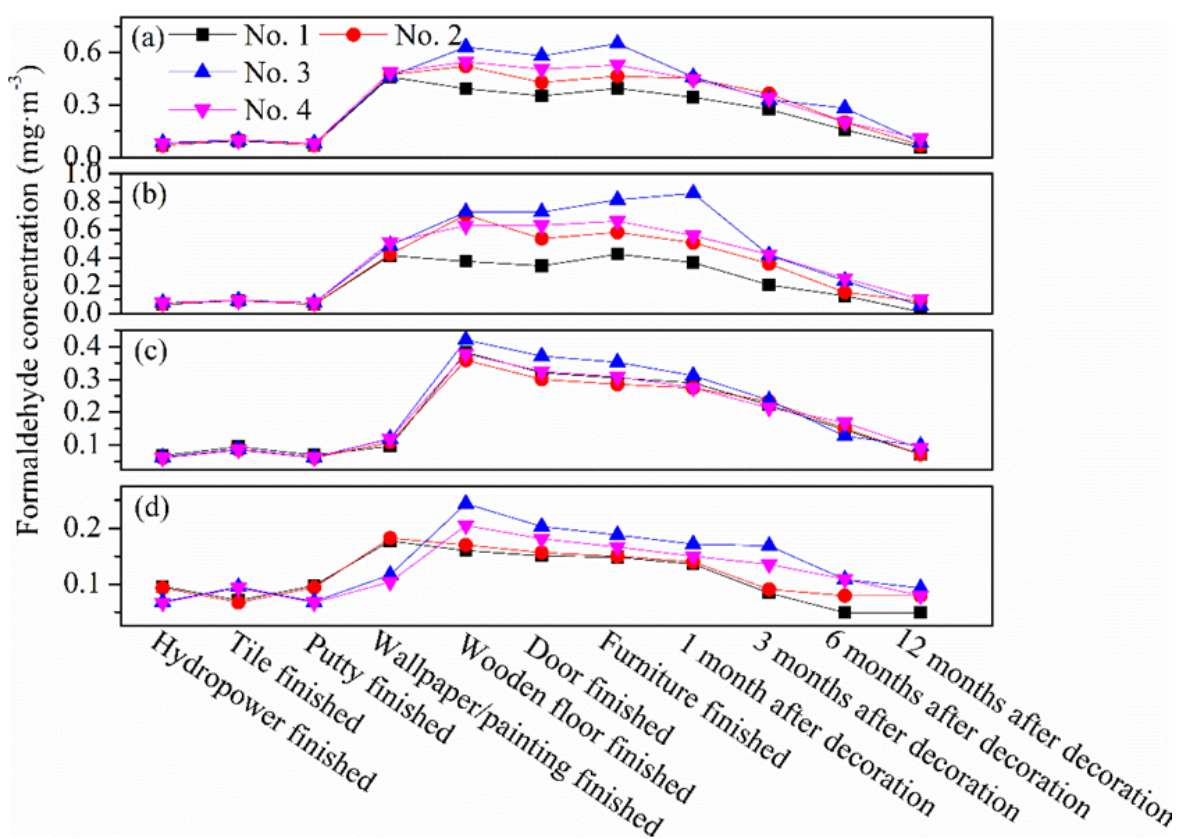

Fig. 2. Concentration of formaldehyde in (a) living room, (b) bedroom, (c) kitchen, and (d) bathroom.

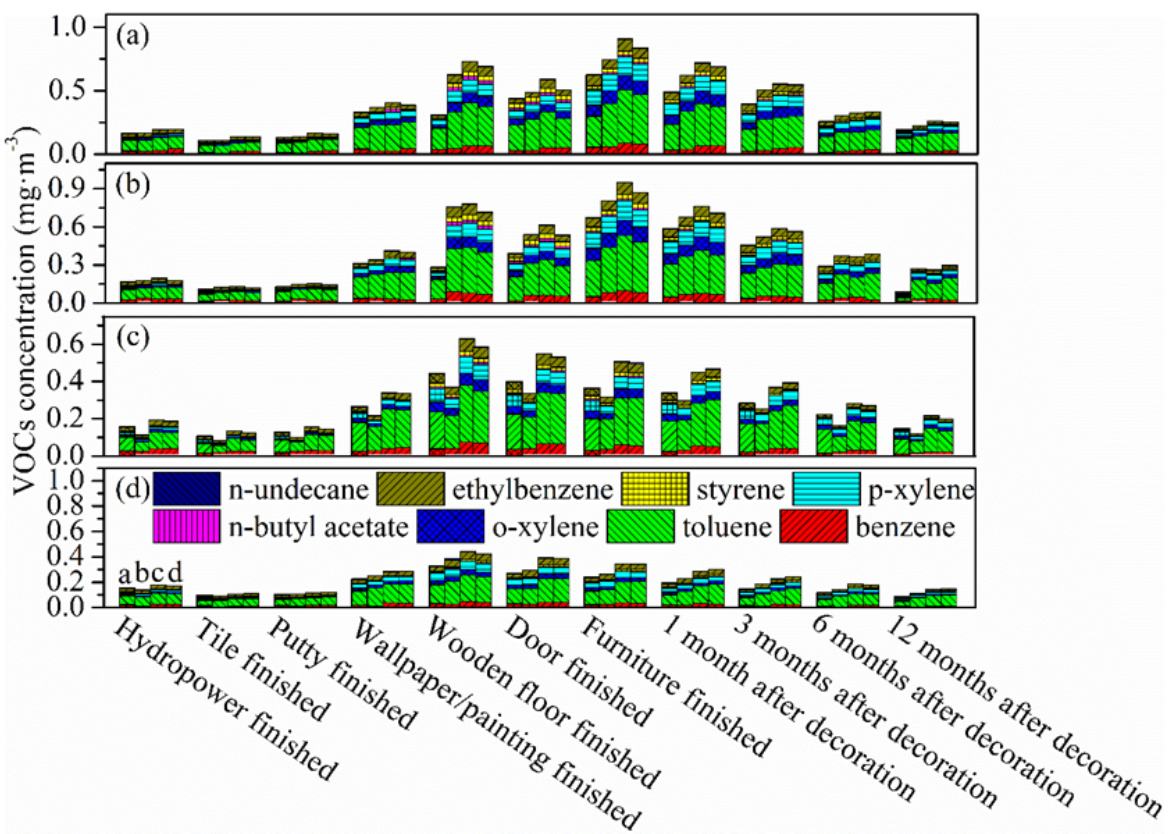

Fig. 3. Concentration of VOCs in (a) living room, (b) bedroom, (c) kitchen, and (d) bathroom (a: No. 1; b: No. 2; c: No. 3; d: No. 4).

narrow range. This manifested that wooden products were the main source of VOCs and formaldehyde. For the kitchen and bathroom, the indoor formaldehyde and VOCs concentrations increased continually after the cupboard installation and then decreased gradually as a function of time. In addition, it was noteworthy that the indoor formaldehyde and VOCs concentrations presented a downward trend after the decorating had been completed. The indoor formaldehyde concentration decreased to limits of $0.1 \mathrm{mg} \mathrm{m}^{-3}$ (GB/T 18883-2002) when the decoration was completed after 1 year, and the indoor VOCs concentration fell below the limits of $0.6 \mathrm{mg} \mathrm{m}^{-3}$ (GB/T 18883-2002) when the decoration was completed within 6 months. This phenomenon revealed that the indoor elevated VOCs were related to decorations and could last for a long period, which was in accordance with previous studies (Dai et al., 2017).

Based on the above analysis, it could be concluded that the influence of different decorating stages might be mainly attributed to different decorating materials. Thus, the effect of different materials on the variation in indoor formaldehyde and VOCs concentrations of selected apartment units (Nos. 1-4) were investigated further. The 
first 3 apartment units were of the same size and layout and the fourth was larger. The different decorating materials (wall coverings, flooring, and furniture) were listed in Table 3. Table 3, Fig. 2, and Fig. 3 showed that the pollutant concentrations of the 4 room types in No. 1 house were lower than those of the same room types in other apartment units, because of the usage of diverse decorating materials. Conversely, rooms in No. 3 house showed the highest pollution levels because of the usage of diverse decorating materials. Similar decorating materials were used in the rooms in No. 3 and No. 4, but the pollution levels of No. 4 house were lower than those of No. 3 house, which could be attributed to the excellent ventilation of No. 4. All rooms of the same size and with decorating materials possessed a similar variation for the indoor formaldehyde and VOCs concentrations.

\section{Formaldehyde and TVOC Concentrations in 200 Rooms: A Further Investigation on the Effect of Decorating Materials}

As mentioned above, wallpaper, wooden floor and furniture were the main sources of formaldehyde and VOCs. To verify this, formaldehyde and TVOC concentrations were measured in 200 other rooms with different decorating materials. These rooms were decorated within 2 years. The TVOC concentration was referred to the summation of benzene, toluene, $o$-xylene, $p$-xylene, $n$-butyl acetate, ethylbenzene, styrene, and $n$-undecane concentrations. These rooms were sorted into 4 types by decorating materials: a: rooms with emulsion varnish, tile and solid wood composite board; b: rooms with wallpaper, tile and solid wood composite board; c: emulsion varnish, wood floor and solid reinforced composite board; and d: rooms with emulsion varnish, tile and solid wood composite board. As shown in Fig. 4, the formaldehyde concentration followed the sequence: $\mathrm{b}>\mathrm{c}>\mathrm{d}>\mathrm{a}$, while the TVOC concentration followed the sequence: $c>b>a>d$. This was in accordance with the above results.

The above results showed that the indoor formaldehyde and VOCs concentrations of rooms with wallpaper or wooden flooring exceeded those of the same room type with emulsion varnish or tiles, respectively. The introduction of furniture increased the indoor formaldehyde and VOCs concentrations significantly, especially for solid wood furniture. Formaldehyde was the most ubiquitous pollutant during the decorating process and was released mainly from the decorating materials, such as wall paint, furniture, and adhesives (Liu et al., 2017). Moreover, formaldehyde was used widely to strengthen the plate hardness due to its strong adhesive properties (Huang et al., 2016). Among the determined VOCs, toluene was most frequently detected during decorating, which could be attributed to its wide application in decorating materials, solvents, and household products. Our results also showed that decorating may induce a significant increase in indoor concentrations of xylene and ethylbenzene, which was in line with previous studies (Dai et al., 2017).

In summary, indoor pollution sources played a dominant role over outdoor sources, with the bedroom contributing the highest pollution levels among the 4 monitored room types during decorating. Wallpaper, wooden floors, and wooden furniture were important indoor air pollutant sources. The concentration of the most common indoor VOCs decreased dramatically with time. Given this, we used 1year data to determine human inhalation exposure levels, assuming that these levels would be stable for 5 years.

\section{Exposure Risks}

We investigated the health risks of indoor formaldehyde and VOCs in rooms 1 year after decorating. 6 quantified VOCs (benzene, toluene, $o$-xylene, $p$-xylene, styrene, and ethylbenzene) were selected to assess non-cancer effects. The concentrations of these selected VOCs were shown in Fig. 5. The average individual concentrations of formaldehyde

Table 3. Characteristics of decoration materials.

\begin{tabular}{|c|c|c|c|c|c|c|c|}
\hline \multirow[b]{2}{*}{ Site No } & & \multicolumn{2}{|c|}{ Wall covering } & \multicolumn{2}{|c|}{ Flooring } & \multicolumn{2}{|c|}{ Furniture } \\
\hline & & $\begin{array}{l}\text { Emulsion } \\
\text { varnish }\end{array}$ & Wallpaper & Tile & Wood floor & $\begin{array}{l}\text { Solid wood } \\
\text { composite board }\end{array}$ & $\begin{array}{l}\text { Solid reinforced } \\
\text { composite board }\end{array}$ \\
\hline \multirow[t]{4}{*}{ No. 1} & living room & $\sqrt{ }$ & - & $\sqrt{ }$ & - & $\sqrt{ }$ & - \\
\hline & bedroom & $\sqrt{ }$ & - & $\sqrt{ }$ & - & $\sqrt{ }$ & - \\
\hline & kitchen & $\sqrt{ }$ & - & $\sqrt{ }$ & - & - & $\sqrt{ }$ \\
\hline & bathroom & $\sqrt{ }$ & - & $\sqrt{ }$ & - & - & $\sqrt{ }$ \\
\hline \multirow[t]{4}{*}{ No. 2} & living room & - & $\sqrt{ }$ & - & $\sqrt{ }$ & $\sqrt{ }$ & - \\
\hline & bedroom & $\sqrt{ }$ & - & - & $\sqrt{ }$ & $\sqrt{ }$ & - \\
\hline & kitchen & $\sqrt{ }$ & - & $\sqrt{ }$ & - & $\sqrt{ }$ & - \\
\hline & bathroom & $\sqrt{ }$ & - & $\sqrt{ }$ & - & $\sqrt{ }$ & - \\
\hline \multirow[t]{4}{*}{ No. 3} & living room & - & $\sqrt{ }$ & - & $\sqrt{ }$ & - & $\sqrt{ }$ \\
\hline & bedroom & - & $\sqrt{ }$ & - & $\sqrt{ }$ & - & $\sqrt{ }$ \\
\hline & kitchen & $\sqrt{ }$ & - & $\sqrt{ }$ & - & - & $\sqrt{ }$ \\
\hline & bathroom & $\sqrt{ }$ & - & $\sqrt{ }$ & - & - & $\sqrt{ }$ \\
\hline \multirow[t]{4}{*}{ No. 4} & living room & - & $\sqrt{ }$ & - & $\sqrt{ }$ & - & $\sqrt{ }$ \\
\hline & bedroom & - & $\sqrt{ }$ & - & $\sqrt{ }$ & - & $\sqrt{ }$ \\
\hline & kitchen & $\sqrt{ }$ & - & $\sqrt{ }$ & - & - & $\sqrt{ }$ \\
\hline & bathroom & $\sqrt{ }$ & - & $\sqrt{ }$ & - & - & $\sqrt{ }$ \\
\hline
\end{tabular}



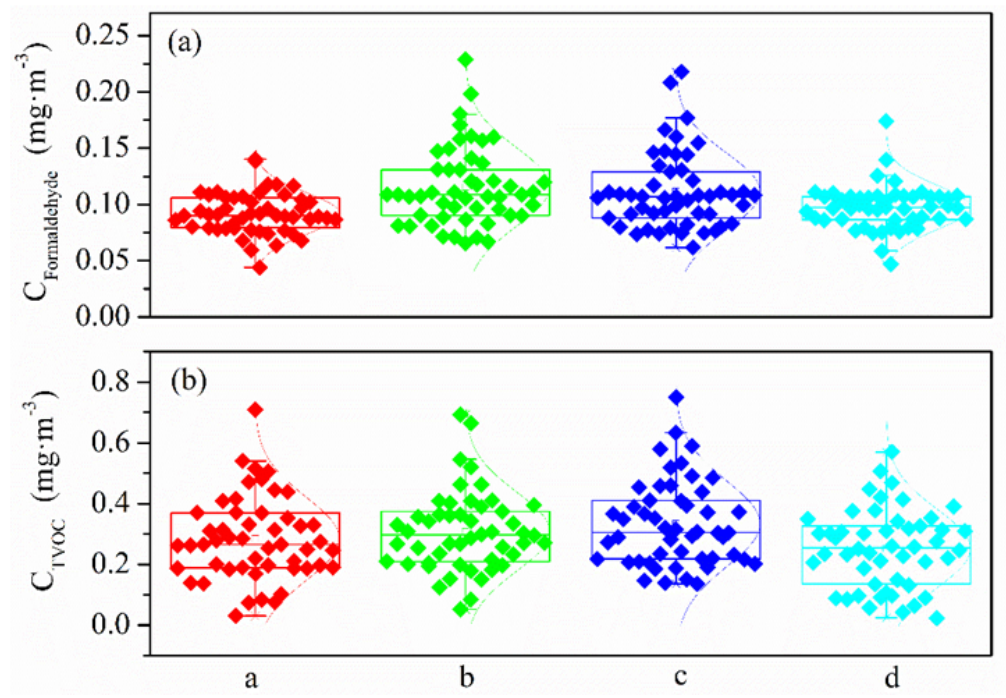

Fig. 4. (a) Formaldehyde and (b) TVOC concentrations in rooms with different decorating materials (a: rooms with emulsion varnish, tile and solid wood composite board; b: rooms with wallpaper, tile and solid wood composite board; c: emulsion varnish, wood floor and solid reinforced composite board; d: rooms with emulsion varnish, tile and solid wood composite board).

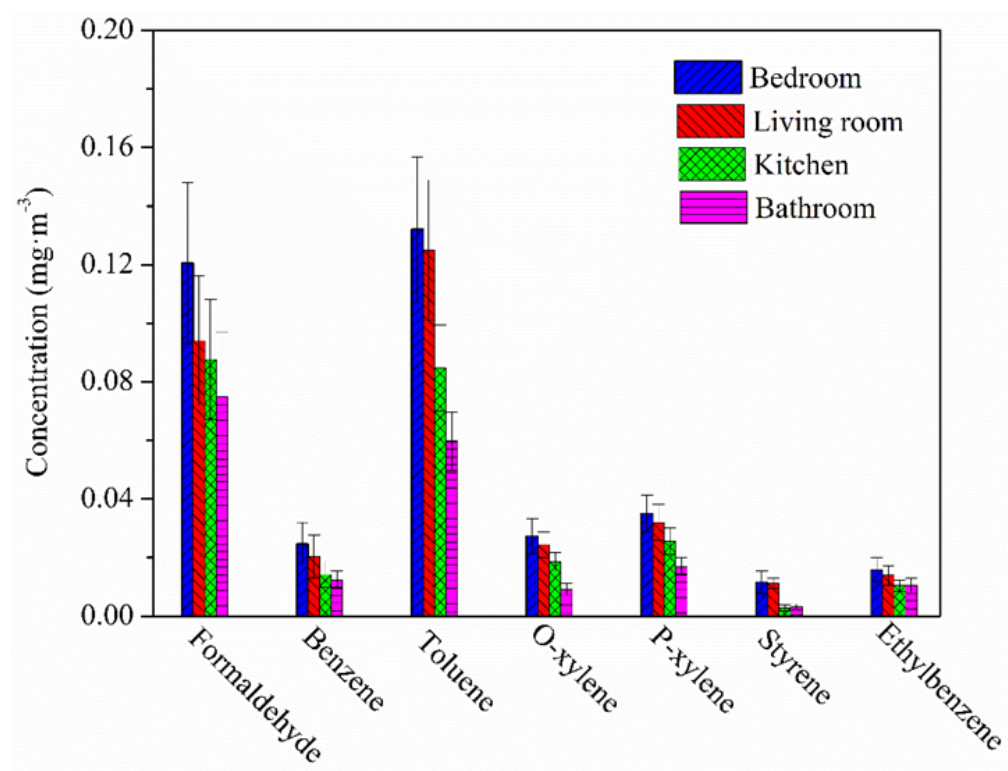

Fig. 5. Concentration of VOCs in rooms 1 year after decoration.

and these 6 VOCs ranged from $0.003 \mathrm{mg} \mathrm{m}^{-3}$ for styrene to $0.13 \mathrm{mg} \mathrm{m}^{-3}$ for toluene. The average concentration of formaldehyde in the living room exceeded the limit specified by national standard GB/T 18883-2002, whereas those in other 3 room types were lower than the limit. The average concentrations of the selected VOCs were lower than the limit specified by national standard GB/T 188832002. The results of the non-cancer effects were displayed in Fig. 6. The results showed that all the HQ and HI of the formaldehyde and VOCs were far less than the threshold $(\mathrm{HQ}=1, \mathrm{HI}=1)(\mathrm{He}$ et al., 2015; Bu et al., 2016), which indicated that the correction between the non-cancer risk and formaldehyde and the selected VOCs was negligible. The HQ and HI of formaldehyde and the selected VOCs in the bedroom were higher than those in the living room. The HQ and HI of formaldehyde and the selected VOCs were highest for children, followed by women and men. The maximum HI with a value of 0.15 was obtained for children in the bedroom and revealed that children were more susceptible than adults in the same environment.

This study also evaluated the CR that was associated with 3 selected VOCs (benzene, styrene, and ethylbenzene) for newly decorated apartment units 1 year after decoration. As shown in Table 4, the CR value of the selected VOCs in newly decorated apartment units varied as bedroom $>$ living room $>$ kitchen $>$ bathroom. All styrene cancer risk values were lower than the acceptable risk level of $1 \times 10^{-6}$ (proposed by the U.S. EPA), which indicated the unlikely 

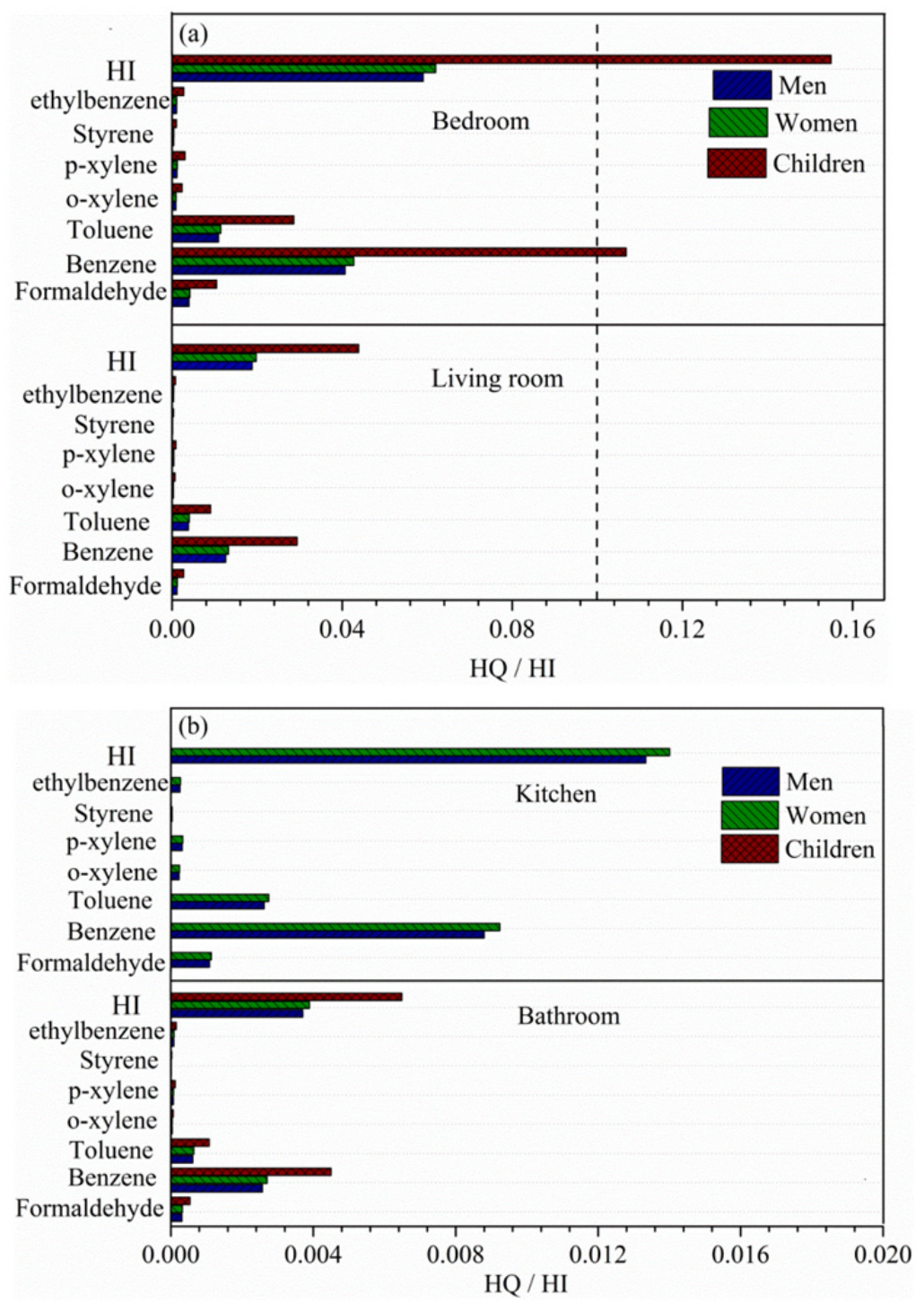

Fig. 6. Indoor VOC non-cancer hazard indexes for the residents in (a) living room and bedroom and (b) kitchen and bathroom.

Table 4. Risk cancer assessment of men, women and children.

\begin{tabular}{|c|c|c|c|c|c|c|c|c|c|c|}
\hline \multirow{2}{*}{ VOCs } & & \multicolumn{3}{|c|}{ Men } & \multicolumn{3}{|c|}{ Women } & \multicolumn{3}{|c|}{ children } \\
\hline & & benzenze & styrene & ethylbenzene & benzenze & styrene & ethylbenzene & benzenze & styrene & ethylbenzene \\
\hline \multirow{4}{*}{$\begin{array}{l}\text { Risk } \\
\left(\times 10^{-6}\right)\end{array}$} & Bedroom & 8.95 & 0.26 & 0.91 & 9.40 & 0.28 & 0.96 & 23.49 & 0.70 & 2.39 \\
\hline & Living room & 2.77 & 0.10 & 0.30 & 2.91 & 0.10 & 0.31 & 6.46 & 0.23 & 0.70 \\
\hline & kitchen & 1.94 & 0.02 & 0.22 & 2.03 & 0.03 & 0.24 & - & - & - \\
\hline & bathroom & 0.57 & 0 & 0.08 & 0.60 & 0.01 & 0.098 & 0.99 & 0.02 & 0.13 \\
\hline
\end{tabular}

association with harmful health risks. The $\mathrm{CR}$ value of partial ethylbenzene exceeded $1 \times 10^{-6}$, but was less than 1 $\times 10^{-5}$, which indicated a probable cancer risk. All benzene cancer risk values exceeded $1 \times 10^{-6}$, from $0.57 \times 10^{-6}$ to $2.35 \times 10^{-5}$. The results demonstrated that children were more vulnerable to indoor VOCs than adults. The CR caused by benzene exposure for children in the bedroom was 2.35 $\times 10^{-5}$, which was approximately 23 times greater than $1 \times$ $10^{-6}$. Thus, indoor benzene contamination was a serious threat to human health, especially for children.

\section{CONCLUSIONS}

Indoor air pollution, which poses a significant threat to human health, has become a serious topic because of the increasing variety in decorating materials. We investigated the characteristics of $\mathrm{PM}_{2.5}$, formaldehyde, and 8 selected VOCs in 6 newly decorated apartment units during the decorating process in Xi'an, China; our results provide a health risk assessment of formaldehyde and partial VOCs in the bedroom, living room, kitchen, and bathroom 1 year 
after decorating for both children and adults. Whereas indoor $\mathrm{PM}_{2.5}$ mostly originated outdoors, indoor formaldehyde and VOCs originated primarily in the decorating materials. The formaldehyde and VOC concentrations decreased in the order of bedroom $>$ living room $>$ kitchen $>$ bathroom, mainly due to using different decorating materials, and were strongly related, in particular, to wallpaper, wooden flooring, and wooden furniture. This conclusion was further verified by sampling data for formaldehyde and VOC concentrations measured in 200 other rooms decorated within 2 years in Xi'an. The highest $\mathrm{HI}$ of the indoor formaldehyde and VOCs in the monitored rooms was obtained in the bedroom, followed by the living room, kitchen, and bathroom. The cancer risk assessment showed that benzene, with a $\mathrm{CR}$ of $2.35 \times 10^{-5}$, was the most harmful pollutant among the monitored VOCs.

\section{ACKNOWLEDGEMENTS}

This research was financially supported by the National Science Foundation of China (41573138). Yu Huang is also supported by the "Hundred Talent Program" of the Chinese Academy of Sciences.

\section{REFERENCE}

Afshari, A., Lundgren, B. and Ekberg, L.E. (2003). Comparison of three small chamber test methods for the measurement of VOC emission rates from paint. Indoor Air 13: 156-165.

Batterman, S., Chin, J.Y., Jia, C., Godwin, C., Parker, E., Robins, T., Max, P. and Lewis, T. (2012a). Sources, concentrations, and risks of naphthalene in indoor and outdoor air. Indoor Air 22: 266-278.

Batterman, S., Du, L., Mentz, G., Mukherjee, B., Parker, E., Godwin, C., Chin, J.Y., O'Toole, A., Robins, T., Rowe, Z. and Lewis, T. (2012b). Particulate matter concentrations in residences: An intervention study evaluating stand-alone filters and air conditioners. Indoor Air 22: 235-252.

Bourdin, D., Mocho, P., Desauziers, V. and Plaisance, H. (2014). Formaldehyde emission behavior of building materials: On-site measurements and modeling approach to predict indoor air pollution. J. Hazard. Mater. 280: 164-173.

Bu, Z., Zhang, Y., Mmereki, D., Yu, W. and Li, B. (2016). Indoor phthalate concentration in residential apartments in Chongqing, China: Implications for preschool children's exposure and risk assessment. Atmos. Environ. 127: 34-45.

Chang, T., Ren, D., Shen, Z., Huang, Y., Sun, J., Cao, J., Zhou, J., Liu, H., Xu, H., Zheng, C., Pan, H. and He, C. (2017). Indoor air pollution levels in decorated residences and public places over Xi'an, China. Aerosol Air Qual. Res. 17: 2197-2205.

Cheng, L., Li, B., Cheng, Q., Baldwin, A.N. and Shang, Y. (2017). Investigations of indoor air quality of large department store buildings in China based on field measurements. Build. Environ. 118: 128-143.
Chi, C., Chen, W., Guo, M., Weng, M., Yan, G. and Shen, X. (2016). Law and features of TVOC and Formaldehyde pollution in urban indoor air. Atmos. Environ. 132: 8590.

Dai, H., Jing, S., Wang, H., Ma, Y., Li, L., Song, W. and Kan, H. (2017). VOC characteristics and inhalation health risks in newly renovated residences in Shanghai, China. Sci. Total Environ. 577: 73-83.

Dickerson, A.S., Benson, A.F., Buckley, B. and Chan, E.A.W. (2017). Concentrations of individual fine particulate matter components in the USA around July $4^{\text {th }}$. Air Qual. Atmos. Health 10: 349-358.

Durmusoglu, E., TaspiNar, F. and Karademir, A. (2010). Health risk assessment of BTEX emissions in the landfill environment. J. Hazard. Mater. 176: 870-877.

Gong, Y., Wei, Y., Cheng, J., Jiang, T., Chen, L. and Xu, B. (2017). Health risk assessment and personal exposure to Volatile Organic Compounds (VOCs) in metro carriages - A case study in Shanghai, China. Sci. Total Environ. 574: 1432-1438.

Gratt, L.B. (1996). Air toxic assessment and management. Van Nostrand Reinhold, New York, USA.

Guo, H., Lee, S.C., Chan, L.Y. and Li, W.M. (2004). Risk assessment of exposure to volatile organic compounds in different indoor environments. Atmos. Res. 94: 57-66.

Han, Y., Qi, M., Chen, Y., Shen, H., Liu, J., Huang, Y., Chen, H., Liu, W., Wang, X., Liu, J., Xing, B. and Tao, S. (2015). Influences of ambient air $\mathrm{PM}_{2.5}$ concentration and meteorological condition on the indoor $\mathrm{PM}_{2.5}$ concentrations in a residential apartment in Beijing using a new approach. Environ. Pollut. 205: 307-314.

He, Z., Li, G., Chen, J., Huang, Y., An, T. and Zhang, C. (2015). Pollution characteristics and health risk assessment of volatile organic compounds emitted from different plastic solid waste recycling workshops. Environ. Int. 77: 85-94.

Huang, Y., Ho, S.S., Lu, Y., Niu, R., Xu, L., Cao, J. and Lee, S. (2016). Removal of indoor volatile organic compounds via photocatalytic oxidation: A short review and prospect. Molecules 21: 56.

Kephalopoulos, S., Koistinen, K. and Kotzias, D. (2006). Harmonisation of indoor material emissions labelling systems in EU: Inventory of existing schemes. Proceedings of International Workshop on Energy Performance and Environmental Quality of Buildings, July 2006, Milos island, Greece.

Lee, C.W., Dai, Y.T., Chien, C.H. and Hsu, D.J. (2006). Characteristics and health impacts of volatile organic compounds in photocopy centers. Environ. Res. 100: 139-149.

Liu, L.Y., Yu, X.P., Dong, X.K., Wang, Q., Wang, Y.C. and Huang, J.J. (2017). The Research on formaldehyde concentration distribution in new decorated residential buildings. Procedia Eng. 205: 1535-1541.

Mehta, S., Shin, H., Burnett, R., North, T. and Cohen, A.J. (2013). Ambient particulate air pollution and acute lower respiratory infections: a systematic review and implications for estimating the global burden of disease. Air Qual. Atmos. Health 6: 69-83. 
MEPC (Ministry of Environmental Protection of the People's Republic of China) (2013). Exposure factors handbook of chinese population (Adults), China Environmental Press, Beijing (in Chinese).

Park, J.S. and Ikeda, K. (2006). Variations of formaldehyde and VOC levels during 3 years in new and older homes. Indoor Air 16: 129-135.

Pei, X.Q., Song, M., Guo, M., Mo, F.F. and Shen, X.Y. (2013). Concentration and risk assessment of phthalates present in indoor air from newly decorated apartments. Atmos. Environ. 68: 17-23.

Petkova, E.P., Jack, D.W., Volavka-Close, N.H. and Kinney, P.L. (2013). Particulate matter pollution in African cities. Air Qual. Atmos. Health 6: 603-614.

Rumchev, K., Brown, H. and Spickett, J. (2007). Volatile organic compounds: Do they present a risk to our health? Rev. Environ. Health 22: 39-56.

Sofuoglu, S.C., Aslan, G., Inal, F. and Sofuoglu, A. (2011). An assessment of indoor air concentrations and health risks of volatile organic compounds in three primary schools. Int. J. Hyg. Environ. Health 214: 36-46.

Song, P., Wanga, L., Hui, Y. and Li, R. (2015). PM 2.5 Concentrations indoors and outdoors in heavy air pollution days in winter. Procedia Eng. 121: 1902-1906.

Tao, H., Fan, Y., Li, X., Zhang, Z. and Hou, W. (2015). Investigation of formaldehyde and TVOC in underground malls in Xi'an, China: Concentrations, sources, and affecting factors. Build. Environ. 85: 85-93.

Tong, X., Wang, B., Dai, W.T., Cao, J.J., Ho, S.S.H., Kwok, T.C.Y., Lui, K.H., Lo, C.M. and Ho, K.F. (2018). Indoor air pollutant exposure and determinant factors controlling household air quality for elderly people in Hong Kong. Air Qual. Atmos. Health 11: 695-704.

U.S. EPA (1989). Risk Assessment Guidance for Superfund (RAGS). Volume I. Human Health Evaluation Manual (Part A). U.S. Environmental Protection Agency, Office of Emergency and Remedial Response, Washington,
DC, EPA/540/1-89/002.

U.S. EPA (1994). Methods for derivation of inhalation reference concentrations and application of inhalation dosimetry Office of Health and Environmental Assessment Office. Research Triangle Park, NC, EPA/600/890/066F.

U.S. EPA (2011). Exposure Factors Handbook 2011 Edition (Final Report). U.S. Environmental Protection Agency, Washington, DC, EPA/600/R-09/052F.

Verriele, M., Schoemaecker, C., Hanoune, B., Leclerc, N., Germain, S., Gaudion, V. and Locoge, N. (2016). The MERMAID study: indoor and outdoor average pollutant concentrations in 10 low-energy school buildings in France. Indoor Air 26: 702-713.

Wang, S., Ang, H.M. and Tade, M.O. (2007). Volatile organic compounds in indoor environment and photocatalytic oxidation: State of the art. Environ. Int. 33: 694-705.

WHO (2000). Air quality guidelines for Europe. WHO Regional Office for Europe, Copenhagen, Denmark.

Yrieix, C., Dulaurent, A., Laffargue, C., Maupetit, F., Pacary, T. and Uhde, E. (2010). Characterization of VOC and formaldehyde emissions from a wood based panel: Results from an inter-laboratory comparison. Chemosphere 79: 414-419.

Zhang, Y., Xiong, J., Mo, J., Gong, M. and Cao, J. (2016). Understanding and controlling airborne organic compounds in the indoor environment: Mass transfer analysis and applications. Indoor Air 26: 39-60.

Zorpas, A.A. and Skouroupatis, A. (2016). Indoor air quality evaluation of two museums in a subtropical climate conditions. Sustainable Cities Soc. 20: 52-60.

Received for review, July 15, 2018 Revised, October 27, 2018 Accepted, October 30, 2018 